\title{
Conversion of a mesodermalizing molecule, the Xenopus Brachyury gene, into a neuralizing factor
}

\author{
Yi Rao \\ Department of Biochemistry and Molecular Biology, Harvard University, Cambridge, Massachusetts 02138 USA
}

\begin{abstract}
It has been shown previously that a Xenopus homolog of the mouse gene Brachyury, Xbra, can initiate mesodermal differentiation. Here, I report that a Xbra mutant truncated at the carboxyl terminus, B304, has lost the mesodermalizing activity and can block the activity of the wild-type Xbra. Injection of B304 mRNA led to formation of neural structures in animal cap explants. Examination of molecular markers in B304-injected explants shows expression of anterior neural markers in the absence of mesodermal markers, indicating that B304 can cause neuralization without the mediation of mesoderm. Implications of these findings on intracellular mechanisms underlying the initiation of neural differentiation in the ectodermal cells are discussed.
\end{abstract}

[Key Words: Neural induction; Brachyury; Xenopus embryos]

Received January 5, 1994; revised version accepted March 4, 1994.

Classic embryological studies have shown that neural tissue is induced in the animal region of an amphibian embryo by the dorsal blastopore lip and its mesodermal derivatives (Spemann, 1938; Hamburger, 1988). The molecular mechanisms for this cellular communication process are just beginning to be revealed.

On the signal-sending side of this process, two molecules, noggin and follistatin, have recently been shown to have the properties of neural inducers (Lamb et al. 1993; Hemmati-Brivanlou et al. 1994). The mRNAs of both molecules are expressed in the organizer and the notochord. Both proteins are secreted. Most importantly, they can induce isolated animal cap explants to express molecular markers for the neural tissue. Mechanistically, noggin is suggested to act through a putative receptor on the receiving cells (Smith and Harland 1992; Lamb et al. 1993), whereas follistatin may act by blocking the action of activin, a mechanism supported by the finding that a dominant-negative activin receptor also shows similar neural-inducing activity (Hemmati-Brivanlou and Melton 1994).

What acts in the ectodermal cells in the animal region to turn these cells into neural tissue in response to the neural inducer(s) remains largely unknown (Otte and Moon 1992). Based on knowledge accumulated over the last decade from molecular studies of cell fate decisions, a working hypothesis is that inducers from the mesoderm initiate neural development in the ectodermal cells through the activation of one or more transcriptional factors. In the course of a functional dissection of the Xenopus homolog of the mouse Brachyury gene, I have obtained results that suggest intracellular molecular mechanisms underlying the initiation of neural development in the animal region.

The mouse gene Brachyury is required for the formation of posterior structures and the notochord (Bennett 1975; Herrmann et al. 1990|. It is highly conserved in vertebrates; a Xenopus homolog, Xbra, and a zebrafish homolog, $\mathrm{Zf}-\mathrm{T}$, are very similar in primary sequence and expression pattern to the mouse gene (Herrmann et al. 1990; Smith et al. 1991; Schulte-Merker et al. 1992). Loss-of-function mutations of Zf- $\mathrm{T}$ also result in the absence of posterior structures and the entire notochord (Halpern et al. 1993; Schulte-Merker et al. 1994). Brachyury is a putative transcription factor, because the protein is localized to the nucleus (Schulte-Merker et al. 1992; Cunliffe and Smith 1994; Kispert and Herrmann 1994) and can bind specific DNA sequences (Kispert and Herrmann 1993). Xenopus Brachyury is first expressed as a maternal message in the embryos (Smith et al. 1991); the zygotic expression of Xbra appears around stage 9 in the entire marginal zone. As gastrulation proceeds, its expression is restricted to the notochord and to a ring of cells in the posterior region (Smith et al. 1991). In animal cap assays, Xbra expression is shown to be an immediate-early response to basic fibroblast growth factor (bFGF) and activin treatment (Smith et al. 1991). Injection of Xbra mRNA into animal caps results in the formation of mesodermal tissues (Cunliffe and Smith 1992).

I have been trying to dissect the role of Xbra by creating mutant forms that might interfere with its function, and have found that a truncation in its carboxyl termi- 
nus leads to the loss of mesodermalizing activity. This mutant blocked the function of wild type Xbra. Moreover, it could cause the formation of neural tissue.

\section{Results}

\section{Generation of mutant forms of Xbra}

In an effort to generate dominant-negative forms of Xbra, I began by trying to mimic two mouse mutants $T^{\text {wis }}$ and $T^{c}$ (Herrmann et al. 1990; Stott et al. 1993). Both of these mouse mutants are antimorphic alleles in that the phenotype of a heterozygote carrying one of these mutant alleles and a wild-type allele is stronger than that of a heterozygote carrying a null allele and a wild-type allele (Bennett 1975; MacMurray and Shin 1988). Molecularly, both mutants have carboxy-terminal truncations; $T^{\text {wis }}$ has a truncation after amino acid residue 352 because of the insertion of a transposable element (Herrmann et al. 1990 ) and $T^{c}$ has a deletion near the $3^{\prime}$ end of the gene resulting in truncation at amino acid residue 387 , followed by in-frame fusion with 32 unrelated amino acid residues (Stott et al. 1993). Because the additional amino acids in $T^{c}$ and in $T^{\text {wis }}$ are not known to me and because the additional amino acids are not likely to be similar in these mutants, I tried to mimic them by creating simple carboxy-terminal truncations. The corresponding Xenopus mutants are B344 for $T^{\text {wis }}$ and B385 for $T^{c}$.

Further truncations from the carboxyl terminus gave rise to two similar mutants, B306 and B304. They behaved indistinguishably in the embryological experiments described below. They both lacked an amino acid sequence with weak similarity to the transcriptional activation domain of a yeast heat shock transcription factor. The structures of all the mutants are shown schematically in Figure 1A.

Larger truncation of the carboxyl terminus would be predicted to be nonfunctional because the two genetically null no tail (ntl) mutants in zebrafish contained truncations of $\mathrm{Zf}-\mathrm{T}$ at amino acid residues 103 and 245, respectively (Schulte-Merker et al. 1994). The corresponding positions in Xbra are shown in Figure 1A.

\section{Characterization of mesodermalizing activity of Xbra mutants}

I used the animal cap assay to test the activity of Xbra mutants. In vitro-transcribed mRNA was microinjected into the animal pole region of both cells at the two-cell stage. Animal cap explants were isolated at stage 8 and cultured until the desired stages to be assayed for molecular markers or to be fixed for histological examination.

To assay for expression of early mesodermal markers, I extracted RNA at stage 10.5 from animal caps and carried out reverse transcription-polymerase chain reaction (RT-PCR) assays for the general markers of mesoderm induction, Xbra and Mixl (Rosa 1989; Smith et al. 1991). I was able to assay for the endogenous Xbra because the primers for PCR corresponded to sequences in the $3^{\prime}$ untranslated region not contained in the constructs used
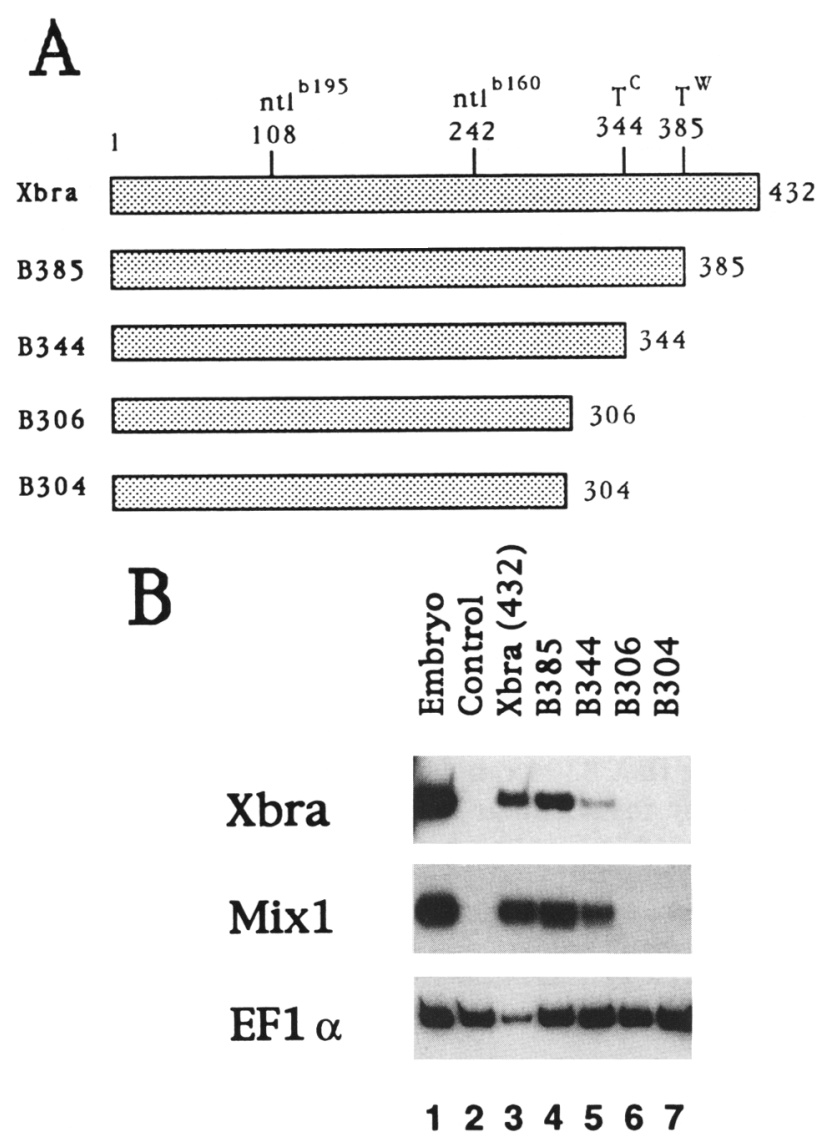

Figure 1. Generation and characterization of Xbra mutants. $(A)$ Xbra contains 432-amino-acid residues and the positions corresponding to truncation points in mouse mutants $\left(T^{\mathrm{c}}, \mathrm{T}^{\mathrm{w}}\right)$ and zebrafish mutants $\left(\mathrm{nt}^{\mathrm{b}}\right)^{\mathrm{b} 95}$ and $\left.\mathrm{ntl}^{\mathrm{b} 160}\right)$ are shown. The Xbra mutant forms are simple truncations at the carboxyl terminus. $(B)$ Animal caps injected with $1 \mathrm{ng}$ of each mRNA were assayed for expression of general mesodermal markers Xbra and Mixl at stage 10.5 by RT-PCR. Lane 1 is from whole embryo RNA as a positive control; lane 2 is uninjected caps as a negative control. EFl $\alpha$ indicates levels of RNA used for RT-PCR (Krieg et al. 1989).

for injection. Injection of Xbra, B385, and B344 led to the expression of these early mesodermal markers while injection of B306 or B304 did not (Fig. 1B).

Xbra has been shown previously to cause the expression of mesodermal markers at later stages (Cunliffe and Smith 1992). My observation that Xbra could induce its own expression supports the hypothesis that there is a positive autoregulation of Brachyury as has been proposed for the mouse and zebrafish homologs (Herrmann 1991; Schulte-Merker et al. 1994). In addition to causing the expression of the early molecular markers, B385 and B344 also led to the formation of mesodermal tissues, including muscle, as demonstrated by histological examination of caps cultured to stage 40 (Fig. 2c,d).

Expression of neural-specific markers in B304injected caps

Injection of B304 was found to neuralize animal caps, as 

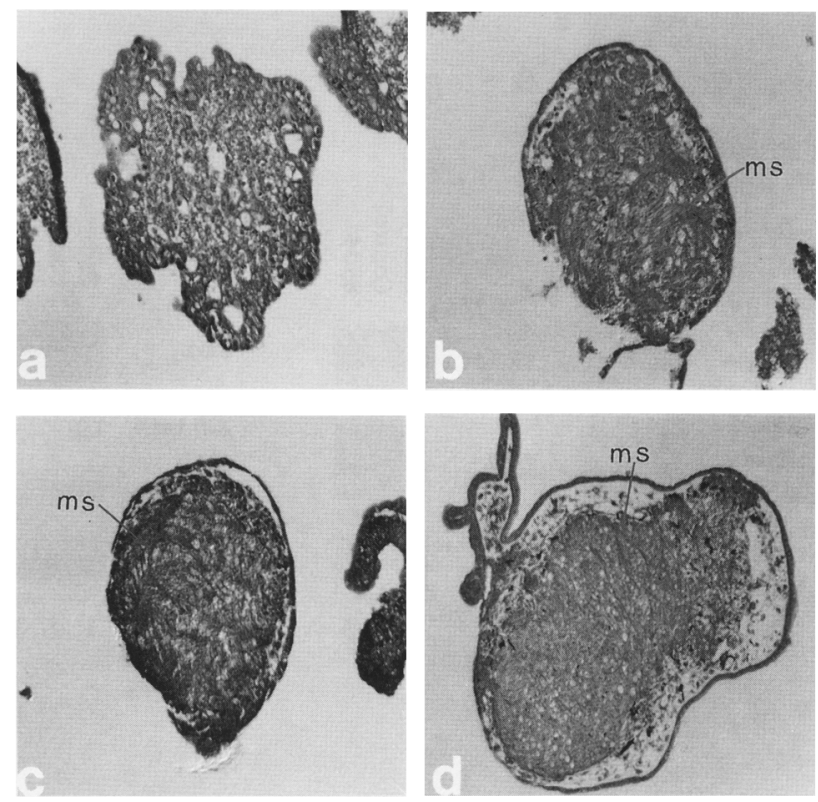

Figure 2. Histology of animal caps injected with Xbra mutants. Sections of stage 40 animal caps either uninjected or injected with $1 \mathrm{ng} /$ embryo of mRNA at the two-cell stage. $(a)$ Uninjected control; (b) Xbra; $(c) \mathrm{B} 385$; (d) B344. (ms) Muscle.

shown by the expression of the neural-specific marker N-CAM (Fig. 3) (Kintner and Melton 1987). The threshold of this effect was $\sim 3 \mathrm{ng}$ of mRNA per embryo, varying somewhat between batches of embryos. This effect did not appear to be attributable to nonspecific toxicity of RNA injection, as injection of the same or higher amount of an mRNA encoding amino acid residues 1-233 of Xbra, the same control used by Cunliffe and Smith (1992), did not result in neuralization (Fig 3A, lane 8). Neither does an mRNA encoding a DNA-binding protein, FosB (Nakabeppu and Nathans 1991), cause neuralization (Fig. 3B).

To characterize the neural tissue in B304-injected caps, I assayed the expression of region-specific neural markers (Fig. 4B). NK2, a forebrain marker (Saha et al. 1993|, and En-2, a marker for the midbrain-hindbrain junction (Hemmati-Brivanlou et al. 1991), were expressed, whereas little expression was detected of a posterior neural marker, XlHbox6 (Wright et al. 1990).

\section{Absence of the expression of dorsal mesodermal markers in B304-injected caps}

There are two ways through which B304 could cause neuralization. It might induce dorsal anterior mesoderm, which then induces anterior neuroectoderm; alternatively, B304 could cause neuralization directly without the mediation of mesoderm. To distinguish between these two possibilities, I assayed for the expression of mesoderm markers in the neuralized caps. Muscle-specific cardiac actin was used at stage 40 as a marker for somites (Gurdon et al. 1985). There was no increase

above the basal level of cardiac actin expression in B304injected caps (Fig. 4B). To examine early mesodermal markers, RNA was extracted at stage 12 from animal caps of the same batch as those expressing neural markers at stage 40 (Fig. 4A). Again, expression of the general mesodermal marker Xbra was not increased. More importantly, expression of noggin, a marker for the Spemann organizer and its derivatives, that is, head mesoderm and the notochord (Smith and Harland 1992), was not increased (Fig. 4A). The expression of goosecoid and follistatin, markers for the Spemann organizer and the head mesoderm (Blumberg et al. 1991, Hemmati-Brivanlou et al. 1994|, were not increased by B304 injection; nor was the expression of forkhead, which is in the mesoderm and the notochord of wild-type embryos (Bolce et al. 1993). These results indicate that the effect of B304 on neural differentiation was not a secondary consequence of dorsal mesoderm formation.

\section{Formation of differentiated neural tissue caused by B304 injection}

In addition to the expression of molecular markers, B304 caused the formation of histologically identifiable neural structures. Pigmented eyes could be observed in some of the B304-injected caps (Figs. 5 and 6). The percentage of caps with eyes is variable so that in different experiments, the numbers of caps with eyes were $11 / 16,1 / 11$, $5 / 13,5 / 17,7 / 13,1 / 14$ (number of caps with eyes/total number of caps). These eyes were usually smaller and less organized than those of whole embryos, although large eyes formed occasionally (Fig. 6B). The pigmented

A
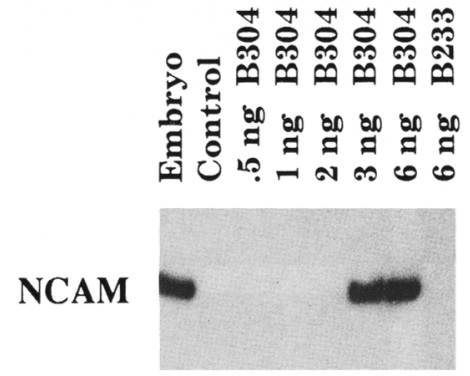

EF1 $\alpha$

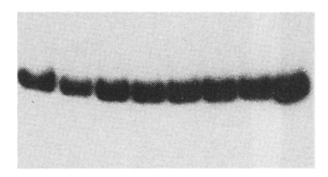

$\begin{array}{llllllll}1 & 2 & 3 & 4 & 5 & 6 & 7 & 8\end{array}$
B

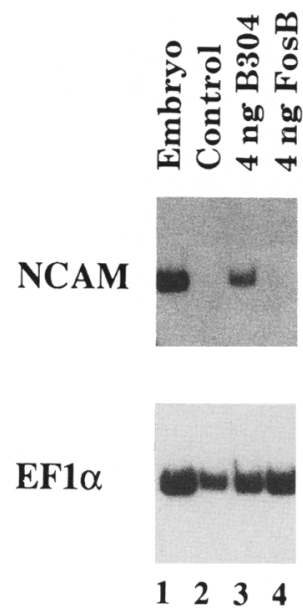

Figure 3. Effect of B304 on N-CAM expression. (A) Increasing doses of B304 mRNA were injected into the embryo. Injection of mRNA encoding a shorter form of Xbra (amino acid residues 1-233) did not result in N-CAM expression at doses similar to, or higher than, that of B304 mRNA. $(B)$ mRNA encoding FosB does not cause N-CAM expression. 
Figure 4. Expression of neural and mesodermal markers in B304-injected animal caps. RNA was extracted from the same batch of injected caps at stage 12 and stage 40 and assayed for expression of molecular markers. In each panel, lane 1 is from the whole embryo, lane 2 is from the uninjected control, and lane 3 is from B304-injected animal caps. (A) Stage 12: XFKH2 (forkhead) as a marker for mesoderm and the notochord; XFS (follistatin) and Gsc (goosecoid) as markers for the Spemann organizer; endogenous Xbra as a general mesodermal marker; noggin as a marker for the Spemann organizer and notochord precursor. $(B)$ Stage 40: N-CAM as a general neural marker; NK2 and En-2 as anterior neural markers; opsin as an eye marker; $\mathrm{Xl}$ Hbox6 as a posterior neural marker; and

A. Stage 12

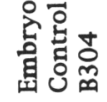

XFKH2

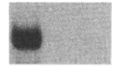

XFS

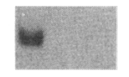

Gsc

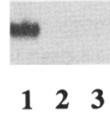

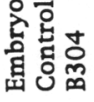

Noggin

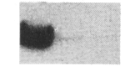

Xbra

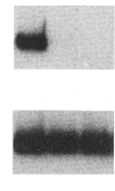

123
B. Stage 40

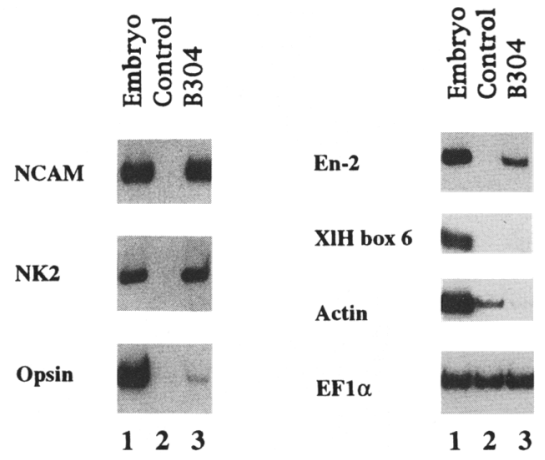
mal marker.

retinal cells are known to be derived from the neural plate in the amphibians (Gilbert 1988; Holt et al. 1988). Expression of a molecular marker specific for photoreceptors-opsin (Saha and Grainger 1993) - was examined in B304-injected caps; it was found to be expressed in these caps but at a lower level than in whole embryos (Fig. 4B). This may be because not all caps had eyes and these eyes were small.

Although neural tubes were occasionally observed (Fig. 6B,C), the neural tissue formed was generally not well-organized (Fig. 6D). For example, the neural tube of normal embryos contains a lightly stained region, called
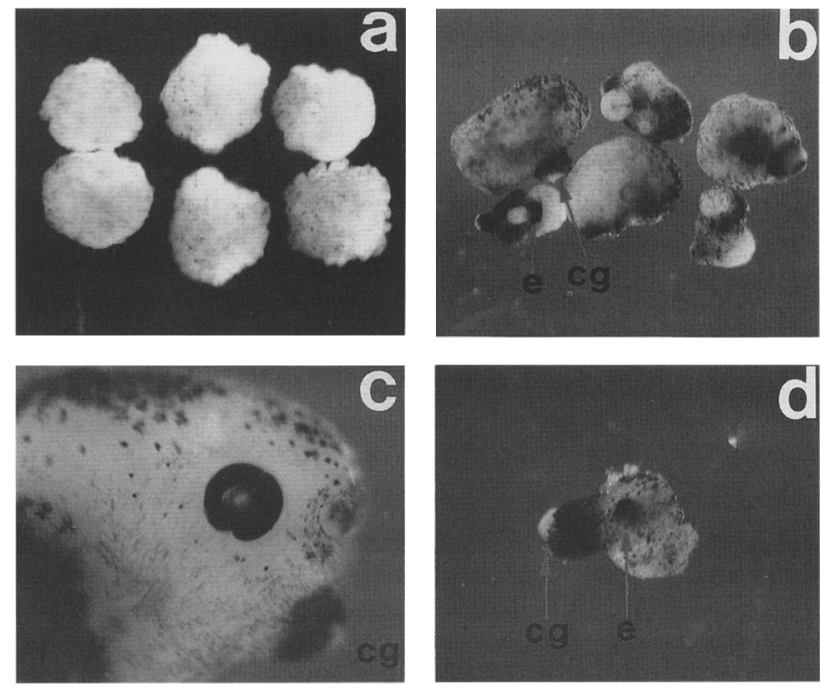

Figure 5. Neural structures in B304-injected animal caps. All caps and embryos shown here are at stage 40 . (a) Control caps; (b) B304-injected caps with eye pigment. (e) eye; (cg) cement gland; $(c)$ Wild-type embryo showing the eye and cement gland $(\mathrm{cg}) ;(d)$ a B304-injected cap. (e) eye; $(\mathrm{cg})$ cement gland. $c$ and $d$ are of the same magnification. the marginal zone, at the ventrolateral periphery (Fig. 6A). In B304-injected caps, the marginal zone-like structure was often found in the middle of a piece of neural tissue (Fig. 6D). The poor organization of neural tissues in B304-injected caps might be attributable to the absence of influence from mesodermal tissues.

\section{Functional antagonism between wild-type Xbra and B304}

Because Xbra has mesodermalizing activity while B304 has neuralizing activity, I examined the relationship between these two phenotypes. I injected different ratios of Xbra and B304 into the embryos and assayed for both neural and mesodermal markers in animal cap explants (Fig. 7).

Four nanograms of B304 alone led to N-CAM expression, whereas injection of Xbra alone (from 0.2 to $5 \mathrm{ng}$ ) increased muscle-specific actin expression. As noted previously (Cunliffe and Smith 1992), different doses of Xbra above a certain threshold induced apparently equal amount of muscle-specific actin expression. Injection of Xbra alone sometimes resulted in a low level of N-CAM expression, presumably as a secondary effect after mesoderm induction. This level, however, was never comparable with those detected in B304-injected caps or whole embryos.

Coinjection of $4 \mathrm{ng}$ of B304 with $0.2 \mathrm{ng}$ of Xbra (20:1 ratio) reduced the expression of muscle-specific actin (Fig. 7, lane 4), demonstrating the B304 could inhibit the mesodermalizing activity of wild-type Xbra. Coinjection of higher amounts of Xbra with B304 resulted in increase of muscle-specific actin expression and reduction of $\mathrm{N}$-CAM expression (lanes 5,6), showing that Xbra can reverse the neuralizing effect of B304. These coinjection experiments reveal functional antagonism between Xbra and B304.

Furthermore, these experiments also provided evi- 

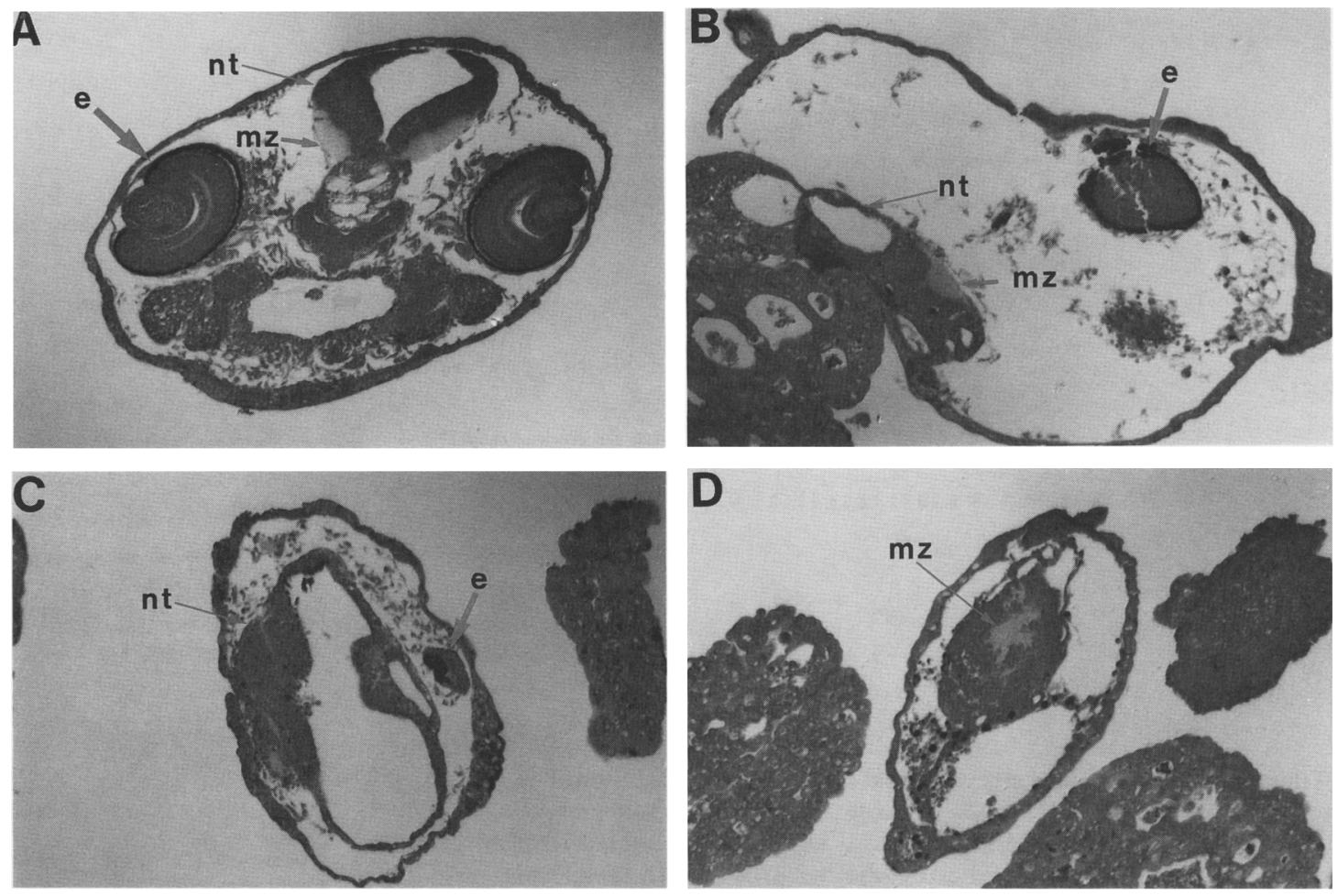

Figure 6. Sections of B304-injected animal caps. (A) A transverse section of a stage 40 wild-type embryo showing the eyes (e), neural tube (nt), and the characteristic marginal zone $(\mathrm{mz}) ;(B)$ a B304-injected cap. The eye here is an atypically large one. $(C)$ A small eye in B304-injected caps; $(D)$ a not well-organized piece of neural tissue surrounding marginal zone-like structure (cf. with mz in $A$ )

dence against the argument that the neuralizing effect of B304 resulted from nonspecific mRNA toxicity. With the amount of B304 constant, addition of more mRNA (Xbra) resulted in less N-CAM expression (lanes 4-6). If $\mathrm{N}$-CAM expression had been the result of nonspecific RNA toxicity, one would have expected to see the same or more N-CAM expression with the addition of more mRNA.

\section{Effect of B304 on animal cap response to $b F G F$ and activin}

Two growth factors, bFGF and activin, are known to be important for mesoderm induction in Xenopus embryos (Kimelman and Kirschner 1987; Slack et al. 1987; Smith 1987; Asashima et al. 1990; Smith et al. 1990; Sokol et al. 1990; Thomsen et al. 1990; van den Eijnden-Van Raaij et al. 1990; Amaya et al. 1991; Hemmati-Brivanlou and Melton 1992). High concentration of activin also leads to neural differentiation, probably secondary to mesoderm induction.

I have observed functional synergism between these growth factors and B304 in inducing the expression of neural markers. Thus, a dose of B304 did not increase N-CAM expression by itself (Fig. 8A lane 15) but it consistently increased the amount of the neural-specific marker N-CAM in response to all doses of bFGF and low doses of activin (Fig. 8A). This occurred even at doses of bFGF or activin that did not induce N-CAM expression by themselves, suggesting a synergy between B304 and bFGF and low-dose activin in neuralization. High doses of activin induce substantial N-CAM expression, which

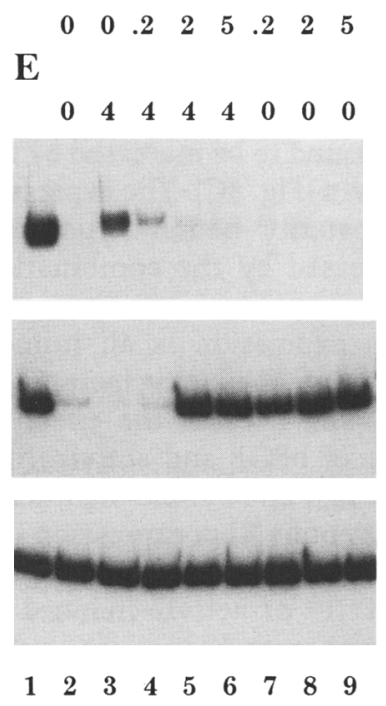

Figure 7. Antagonism between B304 and Xbra. Stage 40 animal caps from embryos injected with either B304 alone (lane 3), Xbra alone (lanes 7-9), or combination of B304 and Xbra (lanes 4-6). Lane 1 is whole embryo; lane 2 is uninjected control caps. The width of lanes in NCAM panel is slightly smaller so that lanes $7-9$ are shifted leftward relative to cardiac actin and EFl $\alpha$ panels. 
A

$$
-+-+-++-+-+-+ \text { B304 }
$$

E $01111220662020001000 \quad$ FGF $(x 10 \mathrm{ng} / \mathrm{ml})$

_. . . . . . . $\stackrel{1: 20}{\stackrel{1}{+}+5}+$ PIF

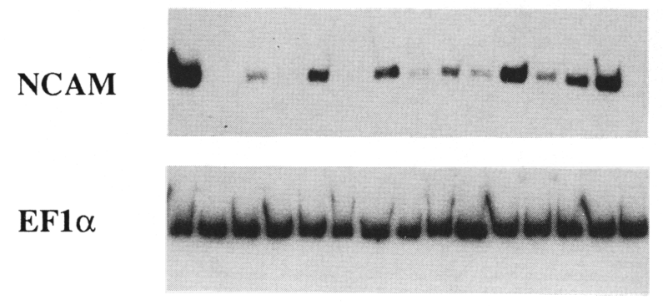

$\begin{array}{lllllllllllllll}1 & 2 & 3 & 4 & 5 & 6 & 7 & 8 & 9 & 10 & 11 & 12 & 13 & 14 & 15\end{array}$

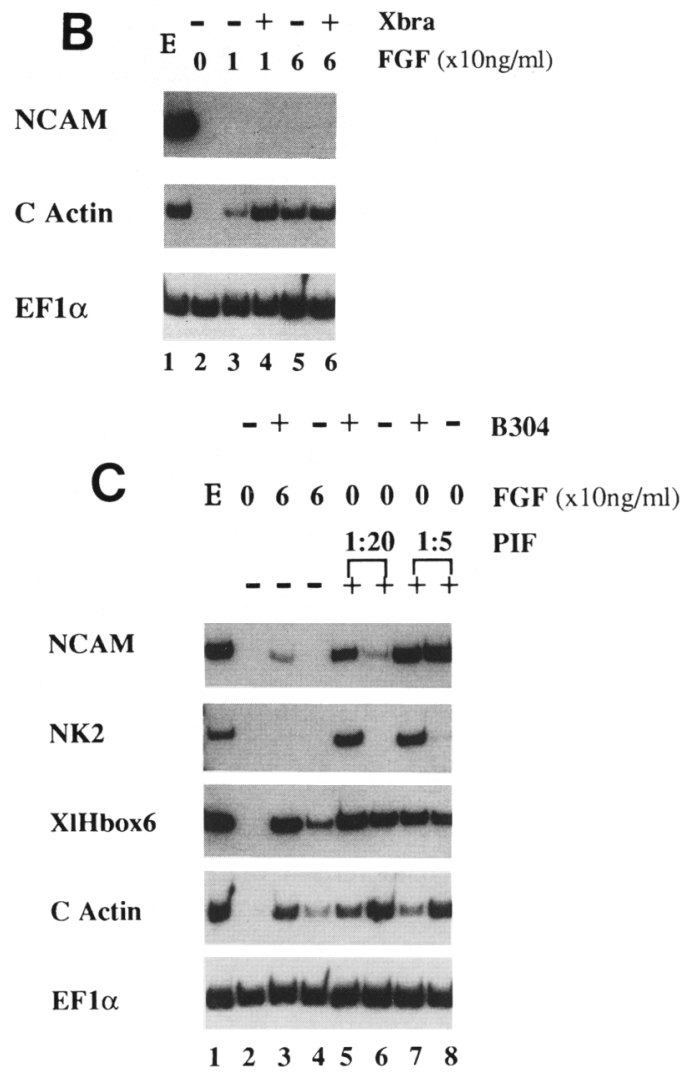

Figure 8. Effect of B304 on the response of animal caps to bFGF and activin. The source of activin is PIF (Sokol et al. 1990). (A) Lane 1 is stage 40 whole embryo as a positive control. Lane 2 is uninjected control caps and not treated with either growth factor. A + or - (top) indicates whether B304 mRNA ( $2 \mathrm{ng})$ had been injected. Numbers in FGF line indicate the concentration of bFGF added $(\times 10 \mathrm{ng} / \mathrm{ml})$. Numbers in the PIF line indicate the dilutions of PIF added. B304 consistently increased the expression of N-CAM at all concentrations of bFGF and low concentration of PIF. $(B)$ The caps were treated in the same way as those in $A$, except that $2 \mathrm{ng}$ of Xbra was injected for those in lanes 4 and 6 . Xbra did not increase N-CAM expression. $(C)$ The caps shown here were treated in the same way as those in $A$. NK2 is an anterior neural marker. XlHbox6 is a posterior neural marker. Muscle-specific cardiac actin is a marker for somitic mesoderm.

is not increased further by B304. Wild-type Xbra did not result in increased expression of N-CAM in animal caps treated with bFGF (Fig. 8B).

When the forebrain marker NK2 was examined, its expression was found to be increased by the combination of B304 and activin (Fig. 8C). The expression of XlHbox6, a marker for posterior neural structure (Wright et al. 1990), was increased by the combination of B304 and bFGF (Fig. 8C).

Because Xbra expression is an immediate early response to mesodermal-inducing factors bFGF and activin (Smith et al. 1991), I tested the effect of B304 on the inductive effect of bFGF and activin in animal caps. I found that although B304 could significantly reduce the amount of endogenous Xbra expression induced by bFGF and low doses of activin at stage 10.5 (data not shown), its effect on bFGF- or activin-induced muscle-specific actin expression at stage 40 was not so obvious (see, e.g., Fig. $8 \mathrm{C})$.

\section{Discussion}

I have generated and characterized a mutant form of Xbra that can block the mesodermalizing activity of wild-type $\mathrm{Xbra}$ in coinjection experiments. Interestingly, the injec- tion of its mRNA initiates neural development in the absence of mesodermal development.

\section{Mutant forms of the Xenopus Brachyury gene}

I found that the Xbra mutants, B385 and B344, that contained the same truncations as the mouse Brachyury antimorphic alleles, $T^{\text {wis }}$ and $T^{c}$, were still able to cause mesodermal differentiation of animal cap explants. It is possible that B385 and B344 did not exactly mimic the mouse mutants that have additional sequences fused inframe after the truncation sites, although this explanation requires the presumably unrelated additional sequences in those two mouse mutants to have similar effects on the function of the amino-terminal portion of the Brachyury protein.

Further deletion at the carboxyl terminus led to two similar forms, B306 and B304, which behaved essentially the same. Neither of them could cause mesodermal differentiation. Injected at or above the ratio of 20:1 (B304 or B306 mRNA/Xbra mRNA), they could block the mesodermal differentiation activity of Xbra.

Neural differentiation initiated by $\mathrm{B} 304$

Injection of B304 mRNA into animal caps resulted in 
neural development. This was demonstrated by the expression of neural-specific molecular markers and by histological examination. In addition to the general neural marker N-CAM, the anterior neural markers, NK2, opsin, and En-2 were also expressed. Little expression of the posterior neural marker XlHbox6 was detected, indicating that the structures formed were primarily anterior.

An interesting feature of neural differentiation caused by B304 was that histologically distinguishable structures were observed. It should be pointed out, however, that the neural tubes were not as well-organized as those in normal embryos and that the fraction of caps with eyes was never $100 \%$. Most of the eyes formed were smaller than those of the wild-type embryos. The poor organization of the neural structures perhaps reflects the lack of influence from the mesoderm.

I was concerned as to whether the neuralizing effect of B304 was the result of mRNA toxicity. Three lines of evidence argue against this possibility. First, injection of an mRNA with further truncation from the carboxyl terminus of Xbra at the same or higher doses did not result in neuralization (Fig. 3A), nor did the injection of an mRNA encoding another DNA-binding protein FosB (Fig. 3B). Second, with the amount of B304 kept constant, addition of Xbra mRNA resulted in less, rather than more, neuralization (Fig. 7). This indicates that the neuralizing effect of $\mathrm{B} 304$ could be reduced by Xbra. It should be noted that the reduction of neuralization could occur without mesodermal differentiation (Fig. 7, lane 4). This observation made it difficult to argue that Xbra increased the tolerance of animal caps to mRNA toxicity by mesodermalizing the caps. Third, neuralizing activity of B304 is also revealed by its synergy with bFGF and activin in inducing N-CAM expression at a dose of B304 that does not cause N-CAM expression by itself (Fig. 8A). In this case, if one argues for B304 RNA toxicity, one would have to conclude that bFGF and activin enhance toxicity. Thus, the neuralizing activity of B304 is unlikely the result of nonspecific RNA toxicity.

The effect of B304 in the whole embryo was not as distinct as that in the animal caps. Noting that B304 can inhibit Xbra activity only at or above the ratio of 20:1 (B304/Xbra) (Fig. 7), it must be difficult for B304 to overcome the high endogenous zygotic Xbra activity. At a low frequency, I observed the formation of a structure resembling an ectopic neural tube in the whole embryo after injection of B304 into the ventral side of the animal region (data not shown).

\section{Antagonism between $\mathrm{B} 304$ and Xbra}

B304 and Xbra initiate different development pathways, one neural, and the other, mesodermal. The two molecules inhibit each other in coinjection experiments. The activity of Xbra appeared more potent in that less of its mRNA was required in the coinjection experiment to antagonize and reverse the neuralizing activity of B304. Coinjection of a certain ratio of B304 and Xbra can re- duce both the mesodermalizing and the neuralizing activities.

Brachyury protein has been proposed to function as a transcription factor because of its nuclear localization and its regulatory role in development (Hermann et al. 1990; Schulte-Merker et al. 1992; Cunliffe and Smith 1994; Kispert and Herrmann 1994), a hypothesis further supported by the recent demonstration of its ability to bind specific DNA sequences (Kispert and Herrmann 1993). The DNA-binding domain of Brachyury has been defined (Kispert and Herrmann 1993) and is contained in B304. Thus, one possible mechanism by which B304 may block Xbra function is to competitively inhibit the DNA-binding activity of Xbra.

\section{Synergistic cooperation between B304 and the growth factors $b F G F$ and activin in neuralization}

It is interesting that in the presence of bFGF or low concentration activin, B304 increased neural marker expression even at doses that could not cause neuralization by themselves. This suggested that bFGF and low concentration of activin induced an activity in the animal cap cells synergistic with B304 in causing neuralization. There are two possible mechanisms underlying this synergism: bFGF could induce expression (directly or indirectly) of another endogenous neuralizing activity at a subthreshold level which then cooperates with B304; alternatively, the bFGF signal transdution pathway could modify the B304 protein directly in a way that increases B304 activity.

\section{Implications on molecular mechanisms underlying the initiation of neural differentiation}

The neuralizing activity of B304 suggests two possible mechanisms operating in the ectoderm to initiate neural differentiation. One possibility is that the low level of maternal Xbra acts to prevent neural differentiation in the ectodermal cells and inhibition of this activity by B304 results in neuralization. The other possibility is that there is an endogenous molecule of the Brachyury family that is expressed in the neuroectoderm and its activity is mimicked by B304. These two possibilities are not exclusive, and a combination of them is possible.

The minimal requirement of the first hypothesis is the existence of maternal Xbra (Smith et al. 1991). This hypothesis is similar to the one proposed for activin (Hemmati-Brivanlou and Melton 1994). In that case, two molecules capable of blocking activin activity, a dominantnegative activin receptor and follistatin, have been shown to be able to induce neural development in the animal caps (Hemmati-Brivanlou and Melton 1994; Hemmati-Brivanlou et al. 1994). It has been proposed that they act by inhibiting a low level of activin activity in animal caps that was below the threshold for mesodermal induction but was necessary for preventing the animal cap cells from taking on the default neural fate (Hemmati-Brivanlou and Melton 1994).

Low levels of activin and Xbra might function in the 
same pathway in preventing neuralization; alternatively, there may be multiple components in the animal region that maintain a balance between taking on the mesodermal or neural fates; this balance could be tilted by promoting one pathway or inhibiting another pathway.

The minimal requirement of the second hypothesis is the existence of a Brachyury family. The evidence for this comes from Drosophila, in which a gene, optomotor blind (omb), has been found to contain a domain highly similar to the amino-terminal portion of Brachyury (Pflugfelder et al. 1992b). omb is required for neural development in the optic lobe of Drosophila (Pflugfelder et al. 1992a). Its product is larger than Brachyury with additional sequences at both the amino and carboxyl termini. B304 contains the entire region of Xbra with sequence similarity to Omb. The second hypothesis therefore suggests that there could be a Brachyury family member that is expressed or activated in neuroectoderm in response to neural-inducing signals from the mesoderm.

In mouse Brachyury mutant embryos, no clear evidence of neural expansion has been presented, although an increase in the number of ectodermal cells and a decrease in that of mesodermal cells was observed (Yanagisawa et al. 1981). The mouse phenotype cannot, however, unambiguously distinguish between the two hypotheses proposed above.

\section{Material and methods}

\section{Construction of mutants}

The coding region of Xbra and its mutant forms were subcloned after fragments were generated by PCR. SP64T was used for Xbra, which has its own stop codon (Krieg and Melton 1984), whereas the carboxy-terminal truncated forms were subcloned into SP64TS, a slightly modified form of SP64T with stop codons added (P. Wilson and D. Melton, pers. comm.). The control construct encoding FosB was also subcloned into SP64T.

\section{Embryo manipulation}

In vitro-transcribed mRNA was injected into the animal pole region of both cells at the two-cell stage. Embryos were cultured in $0.5 \times$ modified Ringer's solution, and animal caps were cut around stage 8 and cultured in $0.5 \times$ modified Ringer's solution with gentamycin. In experiments with growth factors, caps were treated with bFGF or activin at desired concentrations for $1.5 \mathrm{hr}$. The source of activin is PIF-conditioned medium (Sokol et al. 1990).

\section{$R T-P C R$}

RNA was extracted from 10 to 20 caps or embryos at appropriate stages. RNA from 2.5 animal cap equivalent was treated with DNase I and then reverse transcribed with superscript-reverse transcriptase (GIBCO BRL). One-twentieth of the reverse transcription product was used in each PCR reaction with $\left[{ }^{32} \mathrm{P}\right] \mathrm{dATP}$ added. One-fifteenth of the PCR product was loaded in each lane of a $6 \%$ polyacrylamide gel. The primers and PCR conditions were optimized for individual genes examined. The sequences of the primers used here are (cardiac actin) 5' primer, GCT GAC AGA ATG CAG AAG, 3' primer, TTG CTT GGA GGA GTG
TGT; $(\mathrm{EF} 1 \alpha) 5^{\prime}$ primer, CAG ATT GGT GCT GGA TAT GC, $3^{\prime}$ primer, AC TGC CTT GAT GAC TCC TAG; (En-2) $5^{\prime}$ primer, GCT GCA TTT CGC ACT ACT GT, 3' primer, CCT AGT ACA TAT GCA GCT G; (N-CAM) 5' primer, CAC AGT TCC ACC AAA TGC, 3' primer, GGA ATC AAG CGG TAC AGA; (NK2) 5' primer, AG CTT CAC CAG GGC TGT CT, 3' primer, AG GCA GGT GAC TGA CAA GTC; (noggin) 5' primer, AGT TGC AGA TGT GGC TCT, 3' primer, AGT CCA AGA GTC TGA GCA; \{Mixl) 5' primer, AAT GTC TCA AGG CAG AGG, 3' primer, GTG TCA CTG ACA CCA GAA; (Xopsin) 5' primer, TGC CTC ACA CAA TTC CCA TC, $3^{\prime}$ primer, TGG GAG GTG CCT TCA GAC TA; (Xbra) 5' primer, GGA TCG TTA TCA CCT CTG, 3' primer, GTG TAG TCT GTA GCA GCA; (XlHbox6) 5' primer, TAC TTA CGG GCT TGG CTG GA, 3' primer, AGC GTG TAA CCA GTT GGC TG; (XFKH2) 5' primer, GAA CCA CTC TAC TCA CTC, $3^{\prime}$ primer, GAA TGT TGC TGG TCC TAG; (XFS) 5' primer, TTC AGT GCA GCG CTG GAA, 3' primer, TGC GTT GCG GTA ATT CAC.

\section{Histology}

Animal caps or embryos were fixed with Bruin's solution and exchanged into ethanol and xylene before being embedded in wax. Eight-micron sections were cut and stained with Giemsa and mounted with Permount.

\section{Acknowledgments}

I thank D.A. Melton for support; D. Melton, J. Wu, P. Klein, P. Wilson, A. Hemmati-Brivanolou, and $\mathrm{M}$. Ku for discussions and comments on the manuscript; and the Helen Hay Whitney foundation for a postdoctoral fellowship.

\section{References}

Amaya, E., T.J. Musci, and M.W. Kirschner. 1991. Expression of a dominant negative mutant of the FGF receptor disrupts mesoderm formation in Xenopus embryos. Cell 66: 257270.

Asashima, M., H. Nakano, K. Shimada, K. Kinoshita, K. Ishii, H. Shibai, and N. Ueno. 1990. Mesodermal induction in early amphibian embryos by activin A (erythroid differentiation factor). Wilhelm Roux's Arch. Dev. Biol. 198: 330-335.

Bennett, D. 1975. The T-locus of the mouse. Cell 6: 441-454.

Blumberg, B., C.V. Wright, E.M. De Robertis, and K.W. Cho. 1991. Organizer-specific homeobox genes in Xenopus laevis embryos. Science 253: 194-196.

Bolce, M.E., A. Hemmati-Brivanlou, and R.M. Harland. 1993. XFKH2, a Xenopus HNF-3 $\alpha$ homolog, exhibits both activininducible and autonomous phases of expression in early embryos. Dev. Biol. 160: 413-423.

Cunliffe, V. and J.C. Smith. 1992. Ectopic mesoderm formation in Xenopus embryos caused by widespread expression of a Brachyury homolog. Nature 358: 427-430.

- 1994. Specification of mesodermal pattern in Xenopus laevis by interactions between Brachyury, noggin and Xwnt8. EMBO I. 13: 349-359.

Gilbert, S.F. 1988. Developmental biology. Sinaruer Associates, Inc., Sunderland, MA.

Gurdon, J.B., S. Fairman, T.J. Mohun, and S. Brennan. 1985. Activation of muscle specific actin genes in Xenopus development by an induction between animal and vegetal cells of a blastula. Cell 41: 913-922.

Halpern, M.E., R.K. Ho, C. Walker, and C.B. Kimmel. 1993. Induction of muscle pioneers and floor plate is distinguished 
by the zebrafish no tail mutation. Cell 75: 99-111.

Hamburger, V. 1988. The heritage of experimental embryology: Hans Spemann and the organizer Oxford University Press, New York.

Hemmati-Brivanlou, A. and D.A. Melton. 1992. A truncated activin receptor dominantly inhibits mesoderm induction and formation of axial structures in Xenopus embryos. $\mathrm{Na}$ ture 359: 609-614.

Hemmati-Brivanlou, A., J.R. de la Torre, C. Holt, and R.M. Harland. 1991. Cephalic expression and molecular charaterization of Xenopus En-2. Development 111: 715-724.

Hemmati-Brivanlou, A. and D.A. Melton. 1994. Neural induction is a default state in Xenopus embryos when activin receptor signalling is blocked. Cell (in press).

Hemmati-Brivanlou, A., O.G. Kelley, and D.A. Melton. 1994. Follistatin, an inhibitor of activin, is expressed in the Spemann organizer and displays direct neuralizing activity. Cell (in press).

Herrmann, B.G. 1991. Expression pattern of the Brachyury gene in whole-mount $\mathrm{T}^{\mathrm{Wis}} / \mathrm{T}^{\mathrm{Wis}}$ mutant embryos. Development 113: 913-917.

Herrmann, B.G., S. Labeit, A. Poustka, T.R. King, and H. Lehrach. 1990. Cloning of the $\mathrm{T}$ gene required in mesoderm formation in the mouse. Nature 343: 617-622.

Holt, C.E., T.W. Bertsch, H.M. Ellis, and W.A. Harris. 1988. Cellular determination in the Xenopus retina is independent of lineage and birthdate. Neuron 1: 15-26.

Kimelman, D. and M. Kirschner. 1987. Synergistic induction of mesoderm by FGF and TGF $\beta$ and the identification of FGF in the early Xenopus embryo. Cell 51: 869-877.

Kintner, C.R. and D.A. Melton. 1987. Expression of Xenopus N-CAM RNA in ectoderm is an early response to neural induction. Development 99: 311-325.

Kispert, A. and B.G. Herrmann. 1993. The Brachyury gene encodes a novel DNA binding protein. EMBO /. 12: 3211-3220.

1994. Immunohistochemical analysis of the Brachyury protein in wildtype and mutant mouse embryos. Dev. Biol. 161: 179-193.

Krieg, P.A. and D.A. Melton. 1984. Functional messenger RNAs are produced by SP6 in vitro transcription of cloned cDNAs. Nucleic Acids Res. 12: 7057-7070.

Krieg, P.A., S.M. Varnum, W.M. Wormington, and D.A. Melton. 1989. The mRNA encoding elongation factor $1-\alpha(E F-1 \alpha)$ is a major transcript at the midblastula transition in Xenopus. Dev. Biol. 133: 93-100.

Lamb, T.M., A.K. Knecht, W.C. Smith, S.E. Stachel, A.N. Economides, N. Stahl, G.D. Yancopopous, and R.M. Harland. 1993. Neural induction by the secreted polypeptide noggin. Science 262: 713-718.

MacMurray, A. and H.S. Shin. 1988. The antimorphic nature of the $\mathrm{T}^{\mathrm{c}}$ allele at the mouse $\mathrm{T}$ locus. Genetics 120: $545-550$.

Nakabeppu, Y. and D. Nathans. 1991. A naturally occuring truncated form of FosB that inhibits Fos/Jun transcriptional activity. Cell 64: 751-759.

Otte, A.P. and R.T. Moon. 1992. Protein kinase C isozymes have distinct roles in neural induction and competence in Xenopus. Cell 68: 1021-1029.

Pflugfelder, G.O., H. Roth, B. Poeck, S. Kerscher, H. Schwarz, B. Jonschker, and M. Heisenberg. 1992a. The lethal(1)optomotorblind gene of Drosophila melanogaster is a major organizer of the optic lobe development: Isolation and characterization of the gene. Proc. Natl. Acad. Sci. 89: 1199-1203.

Pflugfelder, G.O., H. Roth, and B. Poeck. 1992b. A homology domain shared between Drosophila optomotor-blind and mouse Brachyury is involved in DNA binding. Biochem. Biophys. Res. Comm. 186: 918-925.
Rosa, F.M. 1989. Mix.l, a homeobox mRNA inducible by mesoderm inducers, is expressed mostly in the presumptive endodermal cells of Xenopus embryos. Cell 57: 965-974.

Saha, M.S. and R.M. Grainger. 1993. Early opsin expression in Xenopus embryos precedes photoreceptor differentiation. Mol. Brain Res. 17: 307-318.

Saha, M.S., R.B. Michel, K.M. Gulding, and R.M. Grainger. 1993. A Xenopus homeobox gene defines dorsal-ventral domains in the developing brain. Development 118: 193-202.

Schulte-Merker, S., R.K. Ho, B.G. Herrmann, and C. NüssleinVolhard. 1992. The protein product of the zebrafish homolog of the mouse $\mathrm{T}$ gene is expressed in nuclei of the germ ring and the notochord of the early embryo. Development 116: 1021-1032.

Schulte-Merker, S., F. Van Eeden, M.E. Halpern, C.B. Kimmel, and C. Nüsslein-Volhard. 1994. no tail (ntl) is the Zebrafish homolog of the mouse T (Brachyury) gene. Development (in press).

Slack, J.M.W., B.G. Darlington, J.K. Heath, and S.F. Godsave. 1987. Mesoderm induction in early Xenopus embryos by heparin-binding growth factors. Nature 326: 197-200.

Smith, J.C. 1987. A mesoderm-inducing factor is produced by a Xenopus cell line. Development 99: 3-14.

Smith, J.C., B.M.J. Price, K. Van Nimmen, and D. Huylebroeck. 1990. Identification of a potent Xenopus mesoderm-inducing factor as a homolog of activin A. Nature 345: 729-731.

Smith, J.C., B.M. Price, J.B. Green, D. Weigel, and B.G. Herrmann. 1991. Expression of a Xenopus homolog of Brachyury $(\mathrm{T})$ is an immediate- early response to mesoderm induction. Cell 67: 79-87.

Smith, W.B. and R.M. Harland. 1992. Expression cloning of noggin, a new dorsalizing factor localized to the Spemann organizer in Xenopus embryos. Cell 70: 829-840.

Sokol, S., G.G. Wong, and D.A. Melton. 1990. A mouse macrophage factor induces head structures and organizes a body axis in Xenopus. Science 249: 561-564.

Spemann, H. 1938. Embryonic development and induction. Yale University Press, New York.

Stott, D., A. Kispert, and B.G. Herrmann. 1993. Rescue of the tail defect of Brachyury mice. Genes \& Dev. 7: 197-203.

Thomsen, G., T. Woolf, M. Whitman, S. Sokol, J. Vaughan, W. Vale, and D.A. Melton. 1990. Activins are expressed early in Xenopus embryogenesis and can induce axial mesoderm and anterior structures. Cell 63: 485-493.

van den Eijnden-Van Raaij, A.J.M., E.J.J. van Zoelent, K. van Nimmen, C.H. Koster, G.T. Snoek, A.J. Durston, and D. Huylebroeck. 1990. Activin-like factor from a Xenopus laevis cell line responsible for mesoderm induction. Nature 345: 732-734.

Wright, C.V.E., E.A. Morita, D.J. Wilkin, and E.M. DeRobertis. 1990. The Xenopus XlHbox 6 homeo protein, a marker of posterior neural induction, is expressed in proliferating neurons. Development 109: 225-234.

Yanagisawa, K.O., H. Fujimoto, and H. Urushihara. 1981. Effects of Brachyury (T) mutation on morphogenetic movement in the mouse embryo. Dev. Biol. 87: 242-248. 


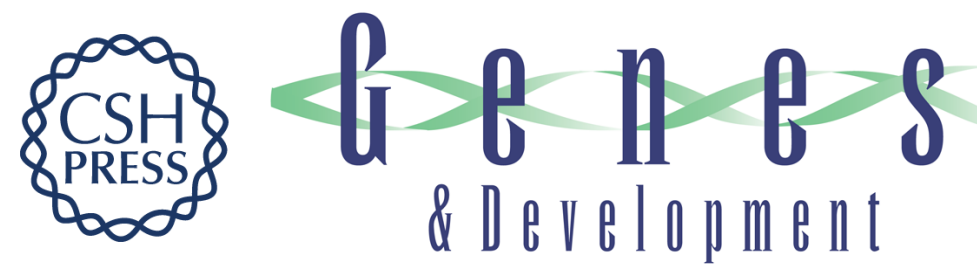

\section{Conversion of a mesodermalizing molecule, the Xenopus Brachyury gene, into a neuralizing factor.}

Y Rao

Genes Dev. 1994, 8:

Access the most recent version at doi:10.1101/gad.8.8.939

References This article cites 41 articles, 13 of which can be accessed free at:

http://genesdev.cshlp.org/content/8/8/939.full.html\#ref-list-1

License

Email Alerting

Service

Receive free email alerts when new articles cite this article - sign up in the box at the top right corner of the article or click here.

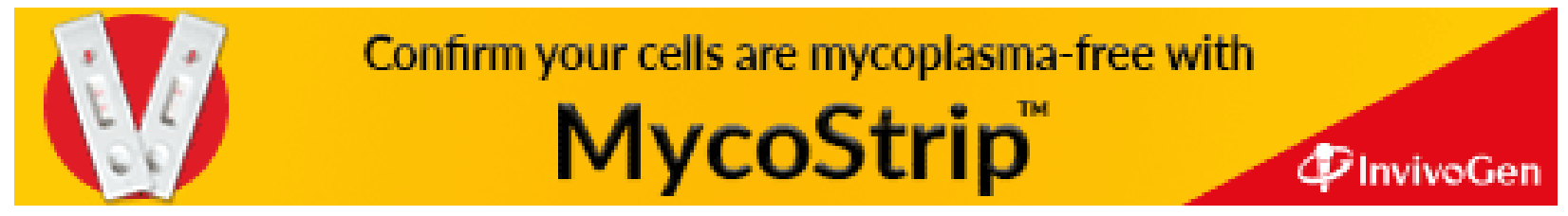

